\title{
Single breathhold 3D balanced SSFP coronary MRA at 3.0T: a reproducibility study
}

\author{
Sahar Soleimanifard ${ }^{1 *}$, Matthias Stuber ${ }^{1,2}$, Allison Hays $^{1}$, Robert G Weiss ${ }^{1}$, Michael Schär ${ }^{1,3}$ \\ From 16th Annual SCMR Scientific Sessions \\ San Francisco, CA, USA. 31 January - 3 February 2013
}

\section{Background}

Balanced steady-state free precession (bSSFP) imaging [1] has developed as the method of choice for coronary MRA at 1.5T. The bSSFP acquisition, however, is especially susceptible to static magnetic field (B0) inhomogeneities and radio frequency transmit field $(\mathrm{B} 1+)$ distortions, both of which are more pronounced at higher field strengths, resulting in degraded and variable image quality at $3.0 \mathrm{~T}$ compared to $1.5 \mathrm{~T}$. Although modified bSSFP sequences have been recently developed [2], these modified implementations too come with notable drawbacks such as longer scan time and lower SNR compared with conventional bSSFP. Therefore, the adoption of bSSFP at 3.0T is still quite limited and it has led to reutilization of spoiled gradient echo techniques at 3.0T, sometimes at the expense of using contrast agents [3]. Recent advances in hardware and software, such as 32-channel receive coils, multitransmit systems, and localized shimming, may however improve the performance of bSSFP at 3.0T. The purpose of this work was to develop an accelerated single breathhold bSSFP sequence at 3.0T taking advantage of these advances, and to test reproducibility of the implemented sequence.

\section{Methods}

A three-dimensional, volume-targeted bSSFP sequence was implemented on a 3.0T MR scanner equipped with multi-transmit system and a 32-channel cardiac phasedarray coil. Image-based shimming was performed using B0-map [4] and B1+-map [5,6] images to minimize field inhomogeneities. Parallel imaging (2.5 SENSE factor with 1.3 oversampling factor) was used to accelerate the acquisition. A half-alpha TR-half preparation pulse with 10 startup RF pulses was used to accelerate the transition to steady-state. Fat suppression was achieved using a spectrally selective saturation pulse. Scan parameters were the following: TR/TE 3.9/1.9 ms, RF excitation angle $50^{\circ}$, field-of-view $300 \times 300 \times 20 \mathrm{~mm}^{3}$, reconstructed voxel size $0.8 \times 0.8 \times 1.0 \mathrm{~mm}^{3}$, acquisition window $105 \mathrm{~ms}$, scan time $20.5 \pm 2.0$ s. 15 healthy volunteers and 3 patients with coronary artery disease (CAD) were included (age 38 \pm 18 (21-75) years; 8 female), and the acquisition was repeated in 9 subjects. The vessel length, diameter, and sharpness were analyzed using the Soap-Bubble reformatting tool [7]. The intra-observer, inter-observer, and inter-scan reproducibilities were quantified using regression analysis and intra-class correlation coefficient, in a blinded manner.

\section{Results}

The bSSFP sequence provided uniform, high quality depiction of coronary arteries as shown in Figure 1. The average visible vessel length of $100.5 \pm 6.3 \mathrm{~mm}$ and sharpness of $55 \pm 2 \%$ compared favorably with earlier reported navigator-gated bSSFP and gradient echo sequences at 3.0 T [8]. As shown in Table 1, an excellent degree of reproducibility was obtained.

\section{Conclusions}

The refined 3D bSSFP acquisition, using a state-of-the-art MR scanner, allows accelerated, reproducible imaging of major coronary arteries during a single breathhold in healthy adult subjects and patients with CAD.

\section{Funding}

NIH/NHLBI (ROIHL084186, ARRA 3R01H108418604S1) and American Heart Association (12PRE115 10006). 


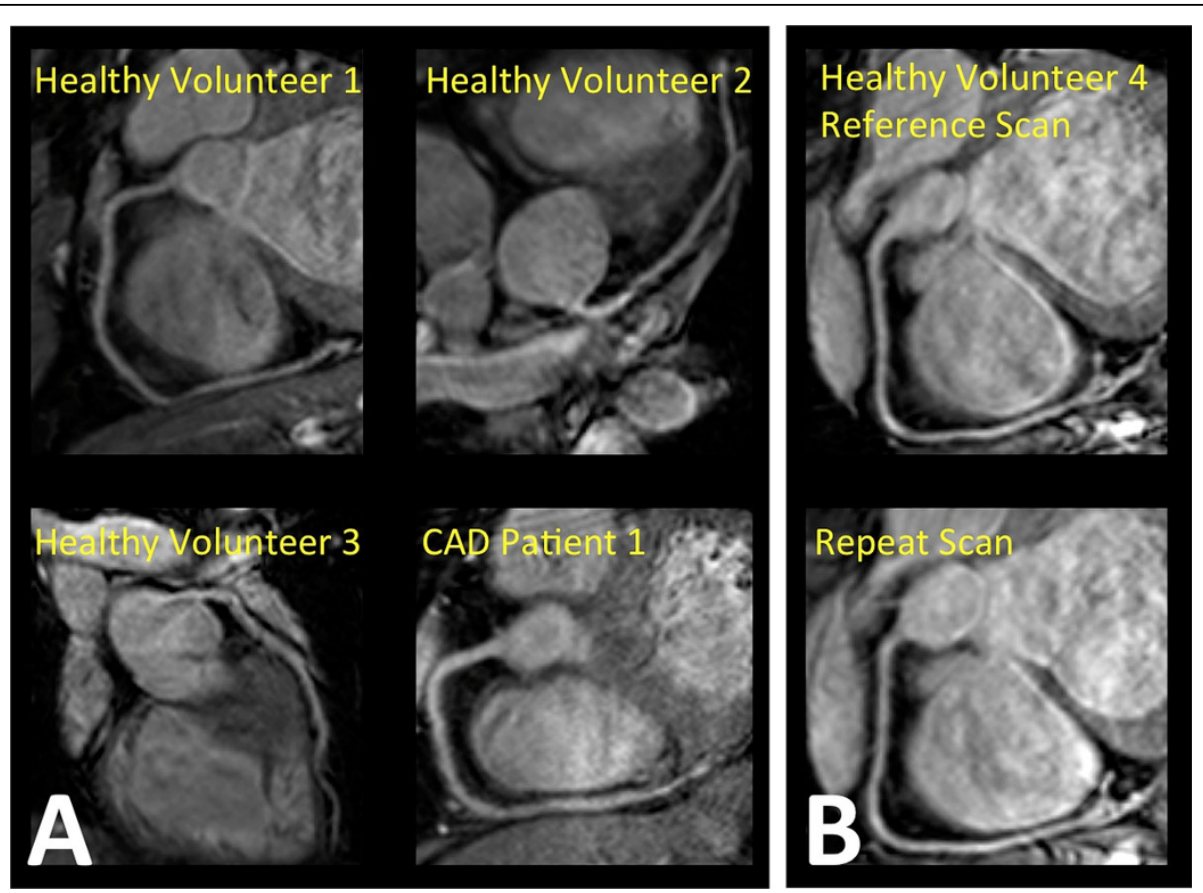

Figure 1 Single breathhold multi-planar reformatted bSSFP images of RCA and LAD in three healthy volunteers and one CAD patient (A). RCA images acquired in two examinations, in a healthy volunteer, demonstrating excellent visual reproducibility (B).

Table 1 Length, diameter, and sharpness of coronary arteries in 18 subjects (RCA = 15, LAD = 5)

\begin{tabular}{cccccccrc}
\hline & \multicolumn{3}{c}{ Intra-observer $(\mathrm{n}=20)$} & \multicolumn{3}{c}{ Inter-observer $(\mathrm{n}=20)$} & \multicolumn{3}{c}{ Inter-scan $(\mathrm{n}=9)$} \\
\hline & Reference analysis & Repeat analysis & ICC & Analysis & ICC & Reference analysis (subset) & Repeat scan analysis & ICC \\
\hline Length $[\mathrm{mm}]$ & $100.5 \pm 6.3$ & $101.6 \pm 6.1$ & 0.993 & $98.7 \pm 6.6$ & 0.896 & $95.7 \pm 10.0$ & $98.2 \pm 9.5$ & 0.974 \\
\hline Diameter $[\mathrm{mm}]$ & $2.8 \pm 0.1$ & $2.8 \pm 0.1$ & 0.987 & $2.8 \pm 0.1$ & 0.976 & $2.7 \pm 0.1$ & $2.8 \pm 0.1$ & 0.961 \\
\hline Vessel Sharpness [\%] & $55 \pm 2$ & $54 \pm 2$ & 0.989 & $56 \pm 1$ & 0.938 & $54 \pm 3$ & $54 \pm 3$ & 0.905 \\
\hline
\end{tabular}

Data are presented as mean \pm SEM. ICC $=$ intra-class correlation coefficient. Diameter and vessel sharpness values are averaged in the entire visualized length of the coronary arteries.

\section{Author details}

${ }^{1}$ Johns Hopkins University, Baltimore, MD, USA. ${ }^{2}$ CIBM \& University of

Lausanne, Lausanne, Switzerland. ${ }^{3}$ Philips Healthcare, Cleveland, OH, USA.

Published: 30 January 2013

\section{References}

1. Electromedica 1986, 54:15-18

2. Lee HL, Shankaranarayanan A, Pohost GM, Nayak KS: Improved coronary MR angiography using wideband steady state free precession at 3 tesla with sub-millimeter resolution. JMRI 2010, 31:1224-29.

3. JACC 2009, 54:69-76.

4. MRM 2004, 51:799-806

5. MRM 2006, 55:1326-33

6. Muella A, Kouwenhoven M, Naehle CP, Gieseke J, Strach K, Willinek WA, Schild $H H$, Thomas D: Dual-source radiofrequency transmission with patient-adaptive local radiofrequency shimming for 3.0-T cardiac MR imaging: initial experience. Radiology 2012, 263:77-85.

7. MRM 2002, 48:658-66.

8. Kaul MG, Stork A, Bansmann PM, Nolte-Ernsting C, Lund GK, Weber C, Adam G: Evaluation of balanced steady-state free precession (TrueFISP) and K-space segmented gradient echo sequences for 3D coronary MR angiography with navigator gating at 3 Tesla. RoFo 2004, 176:1560-65.

\section{doi:10.1186/1532-429X-15-S1-E11}

Cite this article as: Soleimanifard et al:: Single breathhold 3D balanced SSFP coronary MRA at 3.0T: a reproducibility study. Journal of

Cardiovascular Magnetic Resonance 2013 15(Suppl 1):E11.

\section{Submit your next manuscript to BioMed Central and take full advantage of:}

- Convenient online submission

- Thorough peer review

- No space constraints or color figure charges

- Immediate publication on acceptance

- Inclusion in PubMed, CAS, Scopus and Google Scholar

- Research which is freely available for redistribution
Biomed Central 